Disclosure of Interest: J. van der Pol: None declared, S. A. Bergstra: None declared, N. Riyazi: None declared, Y. Goekoop-Ruiterman: None declared, A. Chopra: None declared, P. Kerstens: None declared, W. Lems: None declared, R. Tsonaka: None declared, T. Huizinga Consultant for: UCB, BMS, Pfizer, Roche, Sanofi-Aventis and Boeringher from outside the submitted work., C. Allaart Grant/ research support from: The IMPROVED study was designed by the investigators and financially supported during the first year of follow-up by AbbVie. The BeSt study was supported by the Dutch College of Health Insurances, with an additional grant from Schering-Plough BV and Centocor Inc.

DOI: 10.1136/annrheumdis-2018-eular.1743

\section{SAT0097 RISK OF PREVENTABLE HOSPITALISATION BEFORE AND AFTER DIAGNOSIS AMONG RHEUMATOID ARTHRITIS PATIENTS COMPARED TO CONTROLS}

C.-F. Kuo ${ }^{1,2}$, P.B. Burns ${ }^{3}$, J.-S. Chen ${ }^{2}$, L. Wang ${ }^{4}$, K.C. Chung ${ }^{3} .{ }^{1}$ Academic Rheumatology, University Of Nottingham, Nottingham, UK; ${ }^{2}$ Division of Rheumatology, allergy and Immunology, Chang Gung Memorial Hospital, Taoyuan, Taiwan, Province of China; ${ }^{3}$ Section of Plastic Surgery; ${ }^{4}$ Department of Biostatistics, School of Public Health, University of Michigan, Ann Arbor, USA

Background: Rheumatoid arthritis (RA) generally requires intensive medical intervention, which along with the progression of the disease itself, may lead to the occurrence of comorbidities and hospitalisation that can be prevented with a quality primary care. We assessed the risk of preventable hospitalizations in RA patients, for whom preventable hospitalizations have not been well studied. We compare the incidence rate of preventable hospitalizations in newly-diagnosed RA patients and non-RA patients using data from the Taiwan National Health Insurance (NHI) Database.

Objectives: To investigate the risk of preventable hospitalisation before and after diagnosis between RA and non RA patients.

Methods: 11852 incident RA patients and 59260 age-, sex-, and index yearmatched controls were identified from the Taiwan National Health Insurance Database. Index date was defined as the initial diagnosis date for RA patients and this date was assigned to their matched controls. The incidence and incidence rate ratios (IRRs) of preventable hospitalisation between RA patients and controls were estimated using conditional Poisson regression adjusted for age, sex, Elixhauser Comorbidity Index, number of outpatient visits and hospitalizations 1 year prior to index date, residence urbanisation, income levels, occupation and the number of physicians practicing near the patients' residence.

Results: The overall incidence of preventable hospitalisation in RA patients and controls was 1.71 vs 0.95 events per 1000 person-months, corresponding to adjusted incidence rate ratio (IRR) of $1.43(95 \% \mathrm{Cl}, 1.35-1.51)$. The crude IRR for preventable hospitalisation was 1.84 (1.61-2.11) one year prior to RA diagnosis. Adjusted IRRs $(95 \% \mathrm{Cl})$ for preventable hospitalisation categories were 1.43 (1.22-1.67) for chronic obstructive pulmonary disease, $1.28(1.02-1.62)$ for asthma, $1.76(1.62-1.91)$ for bacterial pneumonia, $1.47(1.35-1.61)$ for urinary tract infection.

Conclusions: This population-based study indicates that RA is independently associated with a higher risk of preventable hospitalisation, and the risk was already greater prior to formal diagnosis of RA. These results signal gaps in the care and management of RA patients in this population.

\section{REFERENCE:}

[1] Billings J, Anderson GM, Newman LS. Recent findings on preventable hospitalizations. Health Aff (Millwood) 1996;15(3):239-249.

Disclosure of Interest: None declared DOI: 10.1136/annrheumdis-2018-eular.6663

\section{SAT0098 \\ PATIENT AND DISEASE CHARACTERISTICS THAT PREDICT SWITCHING FROM A TNF INHIBITOR TO ANOTHER BIOLOGIC OR TARGETED SYNTHETIC DMARD IN PATIENTS WITH RA IN CLINICAL PRACTICE}

L.R. Harrold ${ }^{1}$, H.J. Litman ${ }^{2}$, S.E. Connolly ${ }^{3}$, E. Alemao ${ }^{3}$, S. Kelly ${ }^{3}$, S. Rebello ${ }^{2}$, T. Blachley ${ }^{2}$, J.M. Kremer ${ }^{4}$. 'University of Massachusetts Medical School, Worcester, ${ }^{2}$ Corrona LLC, Waltham; ${ }^{3}$ Bristol-Myers Squibb, Princeton; ${ }^{4}$ Albany Medical College and The Center for Rheumatology, Albany, USA

Background: Specific patient demographics or disease characteristics may be associated with switching from one therapy to another for patients with RA. Identifying these predictive factors may help inform prospective treatment decisions. Objectives: To examine factors predicting switching among patients with RA from a TNF inhibitor (TNFi) to a subsequent biologic (b)DMARD (TNFi or nonTNFi [abatacept, tocilizumab, rituximab]) or the targeted synthetic (ts)DMARD tofacitinib.
Methods: This analysis included patients aged $\geq 18$ years, who were enrolled in a large sequential RA registry established in October 2001 and who initiated a TNFi on/after 1 January 2005 and had $\geq 24$ months' follow-up. Switch was defined as discontinuation of a TNFi and initiation of another bDMARD or tofacitinib within 6 months. Of TNFi initiations, $67 \%$ were randomly selected as a prediction datase and used to develop the final model; $33 \%$ were considered in the validation dataset. Logistic regression modelling was used to predict switching status; baseline demographics (age, sex, race), patient attributes (smoking status, BMI, work status) and clinical characteristics (RF and anti-cyclic citrullinated protein status, erosive disease, history of co-morbidities, prior and current treatment, disease activity, patient-reported pain, fatigue, morning stiffness) were considered. Goodness-of-fit statistics were used to assess model fit and receiver operating charac teristic curves (area under the curve [AUC]) to validate the model.

Results: Among 6909 eligible TNFi initiations, there were 1343 switchers (predic tion dataset: 4623 TNFi initiations, including 898 switchers). Compared with nonswitchers, switchers were younger, had a shorter duration of RA and higher baseline mean CDAI score. Fewer switchers were positive for erosive disease or on combination therapy with MTX, but more were on monotherapy or combination therapy with a non-MTX DMARD. After investigation of several models, the bestfit model (Table) to predict switching from a TNFi yielded an AUC $=0.705$ (sensitivity $=81 \%$; false positive rate $=49 \%$ )

Table 1. Predictive Model for TNFi Switching in Patients with RA

\begin{tabular}{|c|c|c|c|}
\hline Covariate & Value & $\begin{array}{l}\text { Odds ratio } \\
(95 \% \mathrm{Cl})\end{array}$ & $\mathrm{p}$ value \\
\hline Age (10 year effect) & & $0.85(0.79-0.92)$ & $<0.0001$ \\
\hline \multirow[t]{4}{*}{ Duration of RA, years } & $0-2$ & Reference: & \\
\hline & $3-5$ & $0.85(0.67-1.07)$ & 0.17 \\
\hline & $6-10$ & $0.65(0.51-0.85)$ & 0.001 \\
\hline & $>10$ & $0.52(0.41-0.66)$ & $<0.0001$ \\
\hline History of diabetes & & $1.26(0.94-1.68)$ & 0.12 \\
\hline History of malignancy & & $0.66(0.47-0.94)$ & 0.02 \\
\hline History of serious infection & & $1.16(0.82-1.64)$ & 0.41 \\
\hline $\begin{array}{l}\text { Prior number of conventional } \\
\text { DMARDs }\end{array}$ & & $1.17(1.08-1.27)$ & 0.0002 \\
\hline \multirow[t]{3}{*}{ Number of prior non-TNFi } & 0 & Reference: & \\
\hline & 1 & $1.17(0.88-1.55)$ & 0.29 \\
\hline & $\geq 2$ & $1.36(0.90-2.05)$ & 0.15 \\
\hline \multirow[t]{4}{*}{ CDAI score } & Remission (0-2.8) & Reference: & \\
\hline & Low $(>2.8-10)$ & $1.72(1.11-2.66)$ & 0.01 \\
\hline & Moderate (>10-22) & $2.75(1.82-4.16)$ & $<0.0001$ \\
\hline & High (>22) & $2.75(1.82-4.14)$ & $<0.0001$ \\
\hline Year of initiation & & $1.33(1.28-1.37)$ & $<0.0001$ \\
\hline
\end{tabular}

Conclusions: The model identified in this analysis revealed that factors including age, duration of RA, CDAl, history of co-morbid conditions, prior treatment and year of TNFi initiation predicted switching from a TNFi to another bDMARD or tsDMARD.

Disclosure of Interest: L. Harrold Shareholder of: Corrona, LLC, Grant/research support from: Pfizer, Consultant for: Roche, Bristol-Myers Squibb, Employee of: Corrona, LLC, University of Massachusetts Medical School, H. Litman Employee of: Corrona, LLC, S. Connolly Shareholder of: Bristol-Myers Squibb, Employee of: Bristol-Myers Squibb, E. Alemao Shareholder of: Bristol-Myers Squibb, Employee of: Bristol-Myers Squibb, S. Kelly Shareholder of: Bristol-Myers Squibb, Employee of: Bristol-Myers Squibb, S. Rebello Employee of: Corrona, LLC, T. Blachley: None declared, J. Kremer Shareholder of: Corrona, LLC, Grant/research suppor from: AbbVie, Bristol-Myers Squibb, Genentech, Lilly, Novartis, Pfizer, Employee of: Corrona, LLC, Speakers bureau: Genentech (non-branded talks only) DOI: 10.1136/annrheumdis-2018-eular.1581

\section{SAT0099 SARCOPENIA IS ASSOCIATED WITH JOINT DAMAGE IN RHEUMATOID ARTHRITIS: A CROSS-SECTIONAL STUDY}

J.-Z. Lin ${ }^{1}$, Y.-Y. Wang ${ }^{2}$, P.-J. Liu², Y.-Q. Mo ${ }^{1}$, Q.-H. Li ${ }^{1}$, W.-M. Cheng ${ }^{3}$, X.-L. He ${ }^{3}$, L. Dai ${ }^{1} .{ }^{1}$ Rheumatology, Sun Yat-sen Memorial Hospital, Sun Yat-sen University; ${ }^{2}$ Zhongshan School of Medicine, Sun Yat-sen University, Guangzhou; ${ }^{3}$ Shanghai Healthare Co. Ltd, Zhangjiang Innopark, Shanghai, China

Background: The association of metabolic status with disease characteristics of rheumatoid arthritis (RA) remain controversial. Body composition (BC) instead of body mass index (BMI) has been more and more recommended to assess metabolic status.

Objectives: To investigate the characteristics of BC in RA patients and their association with RA disease characteristics.

Methods: BC was assessed in RA patients and control subjects by bioelectric impedance analysis. Overfat was defined by body fat percentage (BF\%) as $\geq 25 \%$ for men and $\geq 35 \%$ for women. Sarcopenia was defined by skeletal muscle mass 